\title{
HUBUNGAN KEAKTIFAN SENAM LANSIA DENGAN KESEIMBANGAN TUBUH PADA LANSIA DI PANTI WERDHA MAJAPAHIT MOJOKERTO
}

\author{
Ariu Dewi Yanti*, Lufita Armayanti** \\ *STIKes Bina Sehat PPNI Mojokerto, Jawa Timur
}

\begin{abstract}
Decrease in balance on the elderly can be fixed with various exercise balance. A good balance is needed someone in support to its mobility it everyday. The purpose of this research was to know relationship liveliness following the elderly exercisers with body balance on the elderly in Panti Werdha Majapahit Mojokerto. This Research design was analytic correlational with cohort study approach. The variable are the lifelines following a gymnastic for elderlyas independent variable and the balance of elderly body as dependent variables. This Population were all of elderly in Panti Werdha Majapahit Mojokerto as much as 47 elderly. Samples taken with purposive sampling technique as many as 24 respondents. Data collected with observation sheet about follow gymnastics and questionnaire of bergbalance scale then tested with spearman rhotest. Spearman rho test results showed that's $\rho=0,008, \alpha=0,05$ so that's $\rho<$ aexplained that there is a connection between liveliness of gymnastics with elderly body's balance. The results showed that the more active elderly to follows the gymnastics it will be increasing their independent or well balance their body.This happens because the elderly exercisers indirectly will keep your muscles and joints in order not to experience a decrease in function that will have an impact on the drop in its ability to support the mobility of the elderly. Expected for health care personnel to be more active in the evocativespirit of elderly in following gymnastics by giving a gift or an award on the elderlyare active so they are more motivated to follow gymnastics elderly.
\end{abstract}

\section{Key Words : Body Balance, Elderly, Gymnastics of elderly}

\section{Pendahuluan}

Proses menua dapat menimbulkan berbagai masalah sosial ekonomi, mental, maupun fisik biologik. Pada aspek fisik biologik terjadi perubahan pada beberapa sistem salah satunya sistem muskuloskeletal (Mujahidullah, 2012). Perubahan sistem muskuloskeletal yang terjadi pada lansia yaitu perubahan fungsional otot yang dapat mengakibatkan perubahan bentuk tulang (Pudjiastuti, 2003). Lansia biasanya akan mengalami kehilangan jaringan otot, susunan syaraf, dan jaringan lain sehingga tubuh akan "mati' sedikit demi sedikit (Mujahidullah, 2012). Pada sistem muskuloskeletal termasuk didalamnya adalah tulang, persendian, dan otot-otot akan mengalami perubahan yang dapat mempengaruhi penampilan fisik dan fisiologisnya (Maryam, 2012).

Penurunan fungsi dan kekuatan otot akan mengakibatkan penurunan kemampuan mempertahankan keseimbangan postural atau keseimbangan tubuh lansia. Gangguan keseimbangan tubuh merupakan masalah yang sering terjadi pada lansia. Apabila gangguan keseimbangan ini tidak dikontrol maka akan meningkatkan risiko jatuh dan cedera pada lansia (Kustanto $d k k$, 2007). Penurunan pada massa tulang dapat disebabkan salah satunya karena ketidakaktifan fisik. Efek dari penurunan tulang adalah tulang menjadi lemah, vertebra lebih lunak dan dapat tertekan, serta tulang berbatang panjang kurang dapat menahan sehingga mengakibatkan fraktur. Massa tonus dan kekuatan otot menurun. Semua perubahan ini sangat mempengaruhi rentang gerak secara keseluruhan, keseimbangan dan cara berjalan (Maryam, 2010).

International Health and Nutrition Examination Survey melakukan test keseimbangan pada lebih dari 5000 orang berusia 40 tahun atau lebihdi beberapa Negara maju salah satunya Amerika pada tahun 2014. Survei tersebut menghasilkan 19\% usia kurang dari 49 tahun, 69\% responden berusia $70-79$ tahun, dan $85 \%$ usia 80 tahun atau lebih mengalami ketidakseimbangan. Sepertiga dari responden berusia $65-75$ tahun mengatakan memiliki gangguan keseimbangan yang dapat mempengaruhi kualitas hidup.Menurut WHO prevelansi jatuh pada tahun 2013 sekitar 28$35 \%$ dari penduduk usia 65 tahun keatas 
sedangkan $32-42 \%$ pada usia 70 tahun. Prevalensi lansia jatuh di RSCM pada tahun 2010 sebesar 15,53 persen (285 kasus). Pada tahun 2013 tercatat 15 pasien (dari 146 pasien) yang dirawat karena instabilitas Insiden di rumah-rumah perawatan (nursing home) 3 kali lebih banyak (Nurhayati, 2013). Penelitian lain yang dilakukan Unit Pelayanan Sosial Tresna Werdha (UPSTW) Bangkalan, Jawa Timur, didapatkan hasil bahwa sekitar $63 \%$ lansia ditempat tersebut mengalami gangguan keseimbangan tubuh akibat kelemahan otot ektremitas bawah (Sulianti, 2013).

Hasil survei awal yang dilakukan peneliti pada tanggal 14 Desember 2015 di Panti Werdha Majapahit Mojokerto terdapat jumlah lansia sebanyak 47 orang dan yang mengalami gangguan keseimbangan dengan gejala pusing sebanyak 5 responden $(33,3 \%)$, vertigo sebanyak 2 responden $(13,3 \%)$, penglihatan kabur sebanyak 8 responden $(53,3 \%)$, disorientasi sebanyak 2 responden $(13,3 \%)$, dan penurunan pendengaran sebanyak 7 responden $(46,7 \%)$, sedangkan yang memiliki riwayat jatuh sebanyak 8 responden $(53,3 \%)$ dan membutuhkan bantuan saat berjalan sebanyak 8 responden juga $(53,3 \%)$.Hasil wawancara pada tanggal 14 -15 Desember 2015 dengan 15 lansia diperoleh data dari 15 responden tersebut mereka merasa takut jatuh ketika berjalan karena mereka tidak mampu berjalan dengan baik seperti muda dulu, ada yang harus berpegangan pada tembok ada yang dituntun oleh perawat panti ada juga yang berjalan lambat. Dari 15 responden tersebut yang aktif dalam mengikuti senam lansia sebanyak 7 responden sedangkan yang tidak aktif sebanyak 8 responden.Hasil observasi peneliti pada tanggal 15 Desember 2015 para lansia berjalan jalan dengan membungkuk, dan ada berjalan dengan berpegangan pada tembok atau tongkat karena mereka takut jatuh, juga terdapat lansia yang berjalan dengan meraba tembok karena penglihatan mereka agak kabur.

Darmojo (2009) melaporkan bahwa penurunan keseimbangan pada lansia tua dapat diperbaiki dengan berbagai latihan keseimbangan. Keseimbangan yang baik sangat diperlukan seseorang dalam menunjang mobilitasnya sehari-hari. Keseimbangan tidak hanya berguna bagi kita sebagai insan olahraga dalam mencapai prestasi, tetapi sangat berguna bagi lansia untuk menjalani masa tuanya tanpa bantuan oranglain. Keseimbangan (balance) adalah kemampuan untuk mempertahankan sistem saraf otot tersebut dalam suatu posisi atau sikap yang efisien selagi kita bergerak. Dampak perubahan morfologis pada otot ini dapat menurunkan kekuatan. Atrofi serabut otot dapat menyebabkan seseorang bergerak menjadi lamban. Penurunan otot ekstremitas bawah dapat mengakibatkan kelambanan gerak, langkah pendek, kaki tidak dapat menapak dengan kuat dan lebih mudah goyah dan menurunya mobilitas lansia (Indardi, 2014).

Penerapan latihan fisik melalui aktifitas olahraga berupa Senam Sehat Indonesia bagi lansia akan membantu menjaga serta membiasakan otot dan sendi agar tetap bergerak, karena dengan bergerak secara tidak langsung akan menjaga otot dan sendi agar tidak mengalami penurunan fungsi yang akan berdampak pada penurunan kemampuannya dalam menunjang mobilitas lansia (Indardi, 2014). Berbagai macam variasi gerakan senam sehat Indonesia dapat dengan mudah diaplikasikan kepada lansia karena telah disesuaikan dengan kondisi fisik lansia. Senam lansia terdiri dari berbagai macam gerakan, tidak hanya terfokus pada satu gerakan saja, hal ini membuat seluruh fungsi tubuh lansia menjadi terlatih dan secara tidak langsung akan menjaga fungsi tubuhnya agar dapat bekerja secara maksimal. Senam lansia dapat dilakukan dalam ruangan ataupun ruangan terbuka, tidak menggunakan peralatan yang mahal dan rumit, serta menyenangkan sehingga dapat mengurangi ketegangan pada lansia (Indardi, 2014).

Pelaksanaan senam lansia di Panti Werdha Majapahit memang sudah dilakukan setiap satu minggu sekali yaitu tepatnya pada hari Jum'at. Jika para lansia mengikuti senam dengan rutin mereka dapat menjaga kesehatan mereka dengan baik, oleh karena itu diperlukan evaluasi pelaksanaan senam lansia terhadap kondisi lansia terutama pada keseimbangan tubuh mereka. Berdasarkan uraian tersebut, peneliti tertarik untuk melakukan penelitian dengan judul hubungan keaktifan mengikuti senam lansia dengan keseimbangan tubuh pada lansia di Panti Werdha Majapahit Mojokerto. 


\section{Metode}

Desain penelitian ini yaitu analitik korelasional dengan pendekatan retrospective cohort study. Variabel peneltiian ini yaitu keaktifan mengikuti senam sebagai variabel independen dan keseimbangan tubuh lansia sebagai variabel dependen. Populasi penelitian yaitu seluruh lansia di Panti Werdha Majapahit Mojokerto sebanyak 47 lansia. Sampel diambil dengan teknik purposive sampling sebanyak 24 responden. Data dikumpulkan dengan lembar observasi mengikuti senam dan kuesioner Skala Ber Balance untuk keseimbangan. Kemudian hasil diuji dengan uji spearman.

Penilaian keaktifan senam lansia disesuaikan dengan frekuensi lansia dalam mengikuti senam selama satu bulan dengan ketentuan :

a. Aktif jika lansia mengikuti senam $\geq 3 x$ dalam sebulan

b. Tidak aktif jika lansia mengikuti senam < $3 \mathrm{x}$ dalam sebulan

Penilaian keseimbangan pada lansia menggunakan skala berg balance scale yang dibuat oleh Berg dkk untuk mengukur keseimbangan yang terdiri dari 14 item yang bernilai $0,1,2,3,4$ dengan skor total minimum 0 (harus memakai kursi roda) dan maksimum 56 (berjalan mandiri). Klasifikasi keseimbangan diinterpretasikan sebagai berikut :

1. $0-20$ : harus memakai kursi roda

2. 21-40: berjalan dengan bantuan

3. 41-56: mandiri

\section{Hasil}

Karakteristik responden berdasarkan Usia Lansia

Tabel 1. Karakteristik responden berdasarkan usia responden di Panti Werdha Majapahit Mojokerto Bulan April 2016

\begin{tabular}{lll}
\hline Usia lansia & F & $\%$ \\
\hline 60-74 tahun & 19 & 79,2 \\
$>74$ tahun & 5 & 20,8 \\
\hline Total & 24 & 100 \\
\hline
\end{tabular}

Sumber Data Primer Mei 2016

Distribusi frekuensi pada tabel 1 diatas menunjukkan bahwa sebagian besar responden berusia 60-74 tahun sebanyak 19 responden $(79,2 \%)$.
Karakteristik responden berdasarkan jenis kelamin

Tabel 2. Karakteristik responden berdasarkan jenis kelamin responden Panti Werdha Majapahit Mojokerto Bulan April 2016

\begin{tabular}{lll}
\hline Jenis kelamin & F & $\%$ \\
\hline Laki-laki & 6 & 25 \\
Perempuan & 18 & 75 \\
\hline Total & 24 & 100 \\
\hline
\end{tabular}

Sumber Data Primer Mei 2016

Distribusi frekuensi responden berdasarkan pada tabel 4.2 diperoleh data sebagian besar responden berjenis kelamin perempuan sebanyak 18 responden (75\%)

Karakteristik responden berdasarkan Jenis Penyakit

Tabel 3. Karakteristik responden berdasarkan jenis penyakit responden Panti Werdha Majapahit Mojokerto Bulan April 2016

\begin{tabular}{lll}
\hline Jenis Penyakit & $\mathrm{F}$ & $\%$ \\
\hline Asam urat & 8 & 33,3 \\
Hipertensi & 10 & 41,7 \\
Herpes & 2 & 8,3 \\
Hernia & 1 & 4,2 \\
Stroke & 1 & 4,2 \\
Gatal-gatal & 1 & 4,2 \\
Luka bakar & 1 & 4,2 \\
\hline Total & 24 & 100 \\
\hline
\end{tabular}

Sumber Data Primer Mei 2016

Distribusi frekuensi responden berdasarkan jenis penyakit responden diperoleh data hampir setengahnya responden menderita penyakit hipertensi sebanyak 10 responden $(41,7 \%)$ dan asam urat sebanyak 8 responden $(33,3 \%)$. 
Karakteristik Responden Berdasarkan Keaktifan mengikuti senam lansia Di Panti Werdha Majapahit Mojokerto

Tabel 4. Karakteristik responden Keaktifan mengikuti senam lansia Di Panti Werdha Majapahit Mojokerto Bulan April 2016

\begin{tabular}{lll}
\hline Keaktifan Senam & F & $\%$ \\
\hline Aktif & 21 & 87,5 \\
Tidak Aktif & 3 & 12,5 \\
\hline Total & 24 & 100 \\
\hline
\end{tabular}

Sumber Data Primer Mei 2016

Distribusi frekuensi responden berdasarkan pada tabel 4.4 diperoleh data bahwa sebagian besar responden aktif dalam mengikuti senam lansia sebanyak 21 responden $(87,5 \%)$.

Karakteristik Responden Berdasarkan Keseimbangan Tubuh Lansia Di Panti Werdha Majapahit Mojokerto

Tabel 5. Karakteristik responden berdasarkan keseimbangan tubuh lansia Di Panti Werdha Majapahit Mojokerto Bulan April 2016

\begin{tabular}{lll}
\hline Keseimbangan Tubuh & F & $\%$ \\
\hline $\begin{array}{l}\text { Memakai Kursi } \\
\text { Berjalan Dengan }\end{array}$ & 6 & 25 \\
$\begin{array}{l}\text { Bantuan } \\
\text { Mandiri }\end{array}$ & & 41,7 \\
\hline Total & 8 & 33,3 \\
\hline
\end{tabular}

Sumber Data Primer Mei 2016

Distribusi frekuensi responden berdasarkan pada tabel 4.5 diperoleh data bahwa hampir setengahnya keseimbangan tubuh responden menunjukkan kategori berjalan dengan bantuan sebanyak 10 responden $(41,7 \%)$
Hubungan Keaktifan Senam dengan Keseimbangan Tubuh Lansia Di Panti Werdha Majapahit Mojokerto

Tabel 6. Tabulasi silang antara keaktifan senam dengan keseimbangan tubuh lansia Di Panti Werdha Majapahit Mojokerto Bulan April 2016

\begin{tabular}{|c|c|c|c|c|c|c|c|c|}
\hline \multirow{3}{*}{$\begin{array}{l}\text { Kea } \\
\text { ktifa } \\
\text { n } \\
\text { Sena } \\
\text { m }\end{array}$} & \multicolumn{6}{|c|}{ Keseimbangan Tubuh } & \multirow{2}{*}{\multicolumn{2}{|c|}{ Total }} \\
\hline & \multicolumn{2}{|c|}{$\begin{array}{l}\text { Memak } \\
\text { ai Kursi }\end{array}$} & \multicolumn{2}{|c|}{$\begin{array}{l}\text { Berjala } \\
\text { n Dng } \\
\text { Bantua } \\
\text { n }\end{array}$} & \multicolumn{2}{|c|}{$\begin{array}{l}\text { Mandir } \\
\text { i }\end{array}$} & & \\
\hline & $\mathrm{F}$ & $\%$ & $\mathrm{f}$ & $\%$ & $\mathrm{f}$ & $\%$ & $\mathrm{f}$ & $\%$ \\
\hline $\begin{array}{l}\text { Tida } \\
\mathrm{k} \\
\text { Akti } \\
\mathrm{f}\end{array}$ & 3 & 100 & 0 & 0 & 0 & 0 & 3 & $\begin{array}{l}10 \\
0\end{array}$ \\
\hline $\begin{array}{l}\text { Akti } \\
\mathrm{f}\end{array}$ & 3 & $\begin{array}{l}14, \\
3\end{array}$ & $\begin{array}{l}1 \\
0\end{array}$ & $\begin{array}{l}47 \\
6\end{array}$ & 8 & $\begin{array}{l}38, \\
1\end{array}$ & $\begin{array}{l}2 \\
1\end{array}$ & $\begin{array}{l}10 \\
0\end{array}$ \\
\hline $\begin{array}{l}\text { Tota } \\
1\end{array}$ & 6 & 25 & $\begin{array}{l}1 \\
0 \\
\end{array}$ & $\begin{array}{l}41, \\
7\end{array}$ & 8 & $\begin{array}{l}33 \\
3\end{array}$ & $\begin{array}{l}2 \\
4 \\
\end{array}$ & $\begin{array}{l}10 \\
0\end{array}$ \\
\hline
\end{tabular}

Berdasarkan tabulasi silang diatas menunjukkan bahwa dari 3 responden yang tidak aktif dalam mengikuti senam seluruhnya memiliki keseimbangan tubuh dalam kategori memakai kursi dan tidak ada lansia yang mandiri. Sedangkan pada 21 responden yang aktif mengikuti senam hampir setengahnya keseimbangan responden dalam kategori berjalan dengan bantuan sebanyak 10 responden $(47,6 \%)$ dan mandiri sebanyak 8 responden $(38,1 \%)$ serta yang memakai kursi sebanyak 3 responden $(14,3 \%)$.

Hasil ujis spearman rho diperoleh data nilai $\rho=0,008, \alpha=0,05$ maka $\rho<\alpha$ berarti $\mathrm{H}_{0}$ ditolak dan $\mathrm{H}_{1}$ diterima sehingga ada hubungan antara keaktifan senam lansia dengan keseimbangan tubuh lansia.

\section{Pembahasan}

Keaktifan senam lansia

Hasil penelitian yang dilakukan di

Panti Werdha Majapahit Mojokerto terhadap 24 responden diperoleh data sebagian besar responden aktif dalam mengikuti senam lansia. Hal ini menunjukkan lansia sudah menyadari bahwa dengan mengikuti senam lansia mereka dapat mejaga kesehatan dan kebugaran tubuh.

Senam lansia adalah olah raga ringan yang mudah dilakukan dan tidak 
memberatkan, yang dapat diterapkan pada lansia. Aktivitas olahraga ini akan membantu tubuh lansia agar tetap bugar dan tetap segar, karena senam lansia ini mampumelatih tulang tetap kuat, mendorongjantung bekerja secara optimal dan membantu menghilangkan radikal bebas yang berkeliaran dalam tubuh (Ismayadi, 2014). Senam lansia ditujukan untuk penguatan, daya tahan dan kelenturan tulang dan sendi, sehingga system muskuloskeletal yang menurun dapat diperbaiki. Senam lansia juga bermanfaat untuk memelihara kebugaran jantung dan paru. Penurunan keseimbangan pada orang tua dapat diperbaiki dengan berbagai latihan keseimbangan (Darmojo,2009).

Hasil penelitian ini menunjukkan bahwa sebagian besar lansia aktif dalam mengikuti senam, hal ini terjadi karena responden merasa bahwa jika mereka aktif mengikuti kegiatan senam lansia, maka mereka akan dapat menjaga kesehatan dan kebugaran tubuh mereka, selain itu senam lansia juga dapat berfungsi mencegah terjadinya penyakit penuaan seperti jantung, hipertensi dll. Keaktifan lansia dalam mengikuti senam lansia ini dipengaruhi oleh beberapa faktor diantaranya usia, dan jenis kelamin.

Hasil penelitian ini menunjukkan bahwa sebagian besar responden berjenis kelamin perempuan. MenurutKomnaslansia(2009)usia harapan hidup perempuandiIndonesia lebihtinggi dibandingkanlaki-laki. Karena banyaknya aktifitasyang dilakukanwanitadibandingkan laki-laki.Parawanita biasanyamenerimaapa yang dialami dan mereka sadar apa yang dialamimerupakansuatu takdirdariTuhan. Salah satu contoh perempuandisamping mencari nafkah, memasak atau menyediakan makan,setiaphari jugaharusmenyediakan sesaji, sertakegiatanrumahtangga lain yang tidak dikerjakan oleh laki-laki (Hikmawati,2008). Hasil penelitian ini menunjukkan bahwa sebagian besar responden termasuk lansia perempuan sehingga mereka mempunyai motivasi yang lebih tinggi daripada lansia laki-laki dalam menjalani aktivitas mereka terutama dalam menjaga kesehatan, karena lansia perempuan mempunyai riwayat aktivitas yang lebih berat daripada seorang laki-laki pada amsa muda, sehingga mereka mempunyai motivasi yang tinggi pula untuk dapat memenuhi kebutuhan sehari-hari terutama dalam melakukan senam lansia untuk menjaga kesehatan mereka.

\section{Keseimbangan Tubuh Lansia di panti Werdha Majapahit Mojokerto}

Hasil penelitian menunjukkan bahwa hampir setengahnya tingkat keseimbangan tubuh responden berada pada kategori dengan bantuan dan memakai kursi dan sebagian kecil berada pada kategori mandiri. Hal ini menunjukkan bahwa proses penuaan membuat penurunan fungsi beberapa organ sehingga lansia membutuhkan bantuan orang lain atau ada peralatan yang digunakan agar mereka dapat menjaga keseimbangan mereka sendiri.

Keseimbangan adalah kemampuan untuk mempertahankan equilibrium baik statis maupun dinamis tubuh ketika ditempatkan pada berbagai posisi (Delitto, 2003). Keseimbangan adalah kemampuan untuk mempertahankan pusat gravitasi atas dasar dukungan, biasanya ketika dalam posisi tegak. Keseimbangan terbagi menjadi 2yaitu statis dan dinamis (Abrahamova \& Hlavacka, 2008). Menurut Batson (2009) faktor-faktor yang mempengaruhi keseimbangan tubuh lansia yaitu pusat gravitasi, garis gravitasi, bidang tumpu, kekuatan otot dan mekanisme otot saat relaksasi.

Seiringbertambahnyausia

responden,maka responden mengalami perubahan fungsional tubuh diantaranya penuruntan kekuatan otot,kerapuhan tulang,dan perubahan fungsional yang lain. Perubahan fungsional otot tersebut antara lain terjadinya penurunan kekuatandankontraksiotot, elastisitas dan fleksibilitas otot, serta kecepatan dan waktu reaksi. Penurunan fungsi dan kekuatan otot akan mengakibatkan penurunan kemampuan mempertahankan keseimbangan posturalataukeseimbangantubuhlansia.

Sedangkan pada lansia yang keseimbangannya dalam kategori duduk di kursi terjadi karena meskipun mereka mengalami penurunan fungsi beberapa organ tubuh yang membuat keseimbangan menjadi terganggu akan tetapi responden tetap berusaha untuk dapat melakukan aktivitas sendiri dan tidak ingin merepotkan orang lain sehingga mereka menggunakan kursi sebagai alat bantu mereka. 
Dan pada responden yang mandiri terjadi karena meskipun usia mereka termasuk usia lansia dan mereka juga mengalami kemunduran secara fisiologis, akan tetapi mereka masih mampu dan kuat untuk melakukan segala sesuatu secara mandiri termasuk menjaga keseimbangan mereka dalam berjalan, berdiri atau beraktivitas.

Hasil penelitian menunjukkan bahwa hampir setengahnya responden berusia 66-70 tahun. Terdapat berbagai perubahan yang berkaitan denganperubahan usiayang dapat mempengaruhi insiden jatuh lansia, terutama ketika perubahan tersebut berefek pada kemampuan fungsional dan menimbulkan gangguan sensori atau gayaberjalandan ketidakstabilan keseimbangan. Identifikasi yang dapat menyebabkan lansia jatuh (misalnya, penyakit), seperti:stroke, demensia, delirium,atau inkontinensia, tetapiada juga lansia dengan penyakityang berhubungan dengan faktorrisikoyangtidak jatuh.Oleh karena itu, risiko jatuh tidak ditentukan semata-mata atas dasar jumlahdan jenis penyakit,tetapi jugapada bagaimana faktor- faktor risiko yang mempengaruhi kemampuan fungsional lansia, khususnya dibidang mobilitas, pengalihan, dan negosiasi dalam lingkungan. Pengaruh kemampuan fungsional memiliki arti penting yang berkaitan dengan jatuhpada lansia dengankelemahandan keterbatasanfungsional fisikyang beradapada risiko terbesar terjadinya jatuh (Lueckenotte, 2000, dalam Nurhayati, 2012). Hasil penelitian ini menunjukkan bahwa semakin bertambahnya usia maka akan lansia akan mengalami penurunan kekuatan otot dan kelentukan akan menyebabkan terjadinya penurunan mobilitas dan keterbatasan gerak pada lansia. Karena keduanya merupakan komponen utama dari kemampuan melangkah, berjalan dan keseimbangan.

\section{Hubungan Keaktifan Senam Lansia dengan Keseimbangan Tubuh Lansia}

Hasil penelitian ini menunjukkan bahwa semakin aktif lansia dalam mengikuti senam lansia maka akan semakin mandiri atau baik keseimbangan tubuh mereka. Hasil uji spearman rho menjelaskan bahwa ada hubungan antara keaktifan senam lansia dengan keseimbangan tubuh lansia.
Senam lansia ditujukan untuk penguatan, daya tahan dan kelenturan tulang dan sendi, sehingga system muskuloskeletal yang menurun dapat diperbaiki. Senam lansia juga bermanfaat untuk memelihara kebugaran jantung dan paru. Penurunan keseimbangan pada orangtua dapat diperbaiki dengan berbagai latihan keseimbangan (Darmojo,2009). Latihan keseimbangan dengan senam lansia berpengaruh yang lebih baik apabila gangguan keseimbangannya disebabkan karena muskuloskleletal (Herawati,2004).

Penerapan latihan fisik melalui aktifitas olahraga berupa Senam Sehat Indonesia bagi lansia akan membantu menjaga serta membiasakan otot dan sendi agar tetap bergerak, karena dengan bergerak secara tidak langsung akan menjaga otot dan sendi agar tidak mengalami penurunan fungsi yang akan berdampak pada penurunan kemampuannya dalam menunjang mobilitas lansia. Berbagai macam variasi gerakan Senam Sehat Indonesia dapat dengan mudah diaplikasikan kepada lansia karena telah disesuaikan dengan kondisi fisik lansia. Senam lansia terdiri dari berbagai macam gerakan, tidak hanya terfokus pada satu gerakan saja, hal ini membuat seluruh fungsi tubuh lansia menjadi terlatih dan secara tidak langsung akan menjaga fungsi tubuhnya agar dapat bekerja secara maksimal. Adanya lansia yang aktif dalam mengikuti senam akan tetapi keseimbangan mereka termasuk kategori memakai kursi dan berjalan dengan bantuan. Hal ini terjadi karena lansia sudah menderita penyakit asam urat atau radang sendi, dimana mereka merasa nyeri jika melakukan aktivitas berdiri secara terus menerus pada daerah persendian, akan tetapi mereka tetap berupaya untuk aktif dalam mengikuti senam tersebut, agar mereka dapat tampak lebih bugar dan dapat berinteraksi dengan teman-teman yang lain.

\section{Simpulan}

Terdapat hubungan antara keaktifan senam lansia dengan keseimbangan tubuh lansia di Panti Werdha Majapahit. Hal ini menunjukkan bahwa senam lansia secara tidak langsung akan menjaga otot dan sendi agar tidak mengalami penurunan fungsi yang akan berdampak pada penurunan kemampuannya dalam menunjang mobilitas lansia. 


\section{Saran}

Bagi Responden

Responden diharapkan untuk dapat lebih intens dan aktif dalam mengikuti senam lansia sehingga mereka dapat mejaga kesehatan dan kebugaran tubuh mereka dengan baik.

Bagi Tenaga Kesehatan

Diharapkan bagi tenaga kesehatan untuk lebih aktif dalam menggugah semangat lansia dalam mengikuti senam lansia di Panti Werdha Majapahit dengan cara memberikan hadiah atau penghargaan pada lansia yang aktif sehingga mereka lebih termotivasi untuk mengikuti senam lansia.

Bagi Peneliti selanjutnya

Bagi peneliti selanjutnya diharapkan dapat menggunakan sampel dan metode yang berbeda seperti faktor yang mempengaruhi keseimbangan lansia antara lain kekuatan otot lansia dan lama waktu penelitian sehingga hasil penelitian dapat membantu mengembangkan ilmu pengetahuan dan teknologi keperawatan khususnya keperawatan gerontik.

\section{Daftar Pustaka}

Abrahamova, D., Hlavacka, F. (2008). AgeRelated Changes of Human Balance During Quiet Stance. Physiological Research, 57, 957-964

Arikunto.2010. Prosedur Penelitian Pendekatan Suatu Praktek. Jakarta : RinekaCipta

Bishop, R.D. \& Hay, J.G. 2009. Basketball: The Mechanics of Hanging in The Air. Medicine and Science in Sports, 11 (3), 274-277.

Batson, G. 2009. Update On Proprioception Considerations For Dance Education. Journal Of Dance Medicine And Science. No.2, Vol. 13.

Chang, Yi Wen, Hong-wen Wu, Wei Hung, Yen-Chen Chiu. 2009. Postural responses in Various Bases of Support and Visual Conditions in the Subjects with Functional Ankle Instability. International journal of Sport and Exercises Science. I (4) : 87-92

Darmojo, Boedhi.2009. Buku Ajar Geriatri Ilmu Kesehatan Usia Lanjut Edisi 4. Jakarta:FKUI.
Dewi.2014. Buku Ajar Keperawatan Gerontik. Yogyakarta : Depublish.

Hidayat, A. Alimul Aziz.2009. Metode Penelitian Kebidanan dan Teknik Analisis Data.

Jakarta : Salemba Medika.

Ismayadi.2014.Pedoman Praktis

Berolahraga Untuk Kebugaran \& Kesehatan.Yogyakarta : ANDI (ISBN : 979-731-416)

Indardi.2014.Peningkatan Keseimbangan Postural Menggunakan Pengukuran Berg Balance Scale (BBS) Pada Lansia Di Sasana Panti Mulyo Sragen.Journal of Sport Sciences and Fitness.

Kemenpora.2000. Pedoman dan Langkahlangkah Senam Lansia. Jakarta : KemenporaRI.

Kustanto,Retno Indarwati, dan Nisfil Mufidah.2007.Peningkatan

Stabilisasi PosturalPada Lansia Melalui Balance Exercise.Surabaya : PSIK FK UNAIR.

Maryam, Siti R. 2012. Mengenal Usia Lanjut dan Perawatannya. Jakarta : Salembs Medika.

Mujahidullah, Khalid.2012.Keperawatan Geriatrik merawat lansia dengan cinta dan kasih sayang. Yogyakarta : Pustaka Pelajar.

Notoatmodjo, Soekidjo.2010.Metodologi Penelitian Kesehatan. Jakarta : Rineka Cipta.

Nurhayati. 2013. PerbedaanKeseimbangan TubuhLansiaBerdasarkan

KeikutsertaanSenam Lansia Di PantiWerdaPelkris PengayomanDan ElimSemarang. Jurnal KeperawatanSTIKESTelogorejo Semarang

Nursalam.2013. Metodologi Penelitian Ilmu Keperawatan. Jakarta : Salemba Medika

Pudjiastuti, Sri Surini.2003. Fisioterapi Pada Lansia.Jakarta : EGC

Setiadi.2013. Konsep Dan Praktik Penulisan Riset Keperawatan.edisi 2.Jakarta : GrahaIlmu

Sulianti. 2013. Gangguan Fisik Pada Lansia. Jakarta: EGC

Suroto.2004. Buku Pegangan Kuliah Pengertian Senam, Manfaat Senam dan Urutan Gerakan. Semarang : 
Unit Pelaksanaan Teknis Mata Kuliah Umum Olahraga Undip.

Suroto.2009. Buku Pegangan Kuliah Pengertian Senam, Manfaat Senam dan Urutan Gerakan. Semarang : Unit Pelaksanaan Teknis Mata Kuliah Umum OlahragaUndip.

Suryabrata. 2011. Metodologi Penelitian. Jakarta : PT. Rajagrafindo Persada 